\title{
СОВРЕМЕННАЯ ПРИВАТИЗАЦИЯ: ЗА И ПРОТИВ
}

\begin{abstract}
АНнотАция. По заявлениям правительства российская экономика начала оживать: отдельные показатели демонстрируют положительную динамику. Однако глубоких структурных изменений не происходит, поэтому рано говорить о выходе страны из кризиса. Правительство продолжает искать источники пополнения государственного бюджета. Так, в последние годы оно инициирует расширение частного сектора экономики за счет постепенной приватизации предприятий, находящихся под контролем государства. В настоящей статье приведена экспертная оценка приватизации российских государственных предприятий в 90-х гг. прошлого века. Приводятся положительные и отрицательные мнения различных авторов по поводу современной приватизации. Делается ссылка на Программу приватизации, принятую Правительством РФ. Описывается механизм приватизации 2017 г. на примере крупнейшей отечественной судоходной компании Совкомфлот. Делаются авторские выводы.
\end{abstract}

кЛюЧЕВЫЕ СЛОВА. Государственные предприятия; приватизация; бюджет; конкуренция; инвесторы.

ИНФОРМАЦИЯ О СТАТЬЕ. Дата поступления 26 апреля 2017 г.; дата принятия к печати 12 мая 2017 г.; дата онлайн-размещения 19 июня 2017 г.

I. V. Dubovik

Baikal State University,

Irkutsk, Russian Federation

\section{MODERN PRIVATIZATION: PRO ET CONTRA}

\begin{abstract}
According to the government, the Russian economy is beginning to revive: separate indicators are demonstrating positive dynamics. However, no profound structural changes take place, Therefore it is early to speak about the country's overcoming the crisis. So, over the last years, it has been initiating expansion of the private sector through gradual privatization of government-controlled enterprises. This article presents an expert assessment of privatizing Russian state-owned enterprises in the 90s of the last century. It brings forth positive and negative opinions of various authors of the current privatization. It refers to the Privatization Program adopted by the Russian Federation Government. It describes the privatization mechanism of 2017 in terms of the largest Russian shipping company Sovkomflot, as well as draws the authors' conclusions.

KEYWORDS. State-owned enterprises; privatization; budget; competition; investors. ARTICLE INFO. Received April 26, 2017; accepted May 12, 2017; available online June 19, 2017.
\end{abstract}

Массовая приватизация государственных предприятий, в которой приняло участие все население страны, проходила в первой половине 90-х гг. прошлого века. Механизм ее осуществления был связан с использованием специально для этого созданных приватизационных ценных бумаг - ваучеров. Их срок существования в соответствии с законодательством закончился в 1996 г. Невозврат к данному способу разгосударствления экономики был подтвержден принятием Федерального Закона «О внесении изменений в подраздел 3 раздела 1 части первой Гражданского кодекса Российской Федерации» № 142 от 2 июля 2013 г., который

\section{Baikal Research Journal}


вступил в силу с 1 октября 2013 г. В связи с данным законом ваучеры были исключены из списка ценных бумаг $\mathrm{P}^{1}$.

Описание процесса приватизации и оценка его перспектив содержатся в трудах российских экономистов конца 1990-х гг., например, В. И. Самарухи [1], М. Бойко [2] и др. В работах начала 2000-х гг. авторы делают попытку оценить итоги приватизации (Ю. В. Перевалов [3], С. Е. Пивоваров [4] и др.). Однако сегодня, по прошествии более 25 лет и пережитых экономических кризисах, можно увереннее говорить о достигнутых результатах.

Резкой критике приватизацию 90-х гг. подвергает, в частности, профессор C. Г. Кара-Мурза, считающий ее непосредственным следствием наблюдаемую в настоящее время коррупцию. $\mathrm{K}$ прямым последствиям приватизации он относит потерю российской промышленностью своей системной целостности и ее структурную деформацию - сдвиг от обрабатывающей к сырьевой промышленности, потерю системообразующих современных отраслей: тракторостроения, авиационной промышленности, фармацевтической и пр., разбалансирование системы цен между промышленностью и остальным хозяйством, эксплуатацию основных фондов «на износ», ликвидацию науки и др. С. Г. Кара-Мурза отмечает, что российская экономика в результате приватизации потеряла свою «мировоззренческую основу». Россия имеет «промышленную систему советского типа, только изуродованную и лишенную потенциала к развитию». Необходимо, по его мнению, «менять тип экономики» [5].

Советник президента РФ С. Ю. Глазьев следствиями приватизации назвал «колоссальную хаотизацию экономики и резкий спад промышленного производства в силу разрушения технологических цепочек». Советская экономика состояла из почти пяти тысяч производственных объединений. Однако эти производственно-технологические комплексы приватизировались не как единое целое, а порознь, что привело к их развалу и краху «всей высокотехнологической промышленности», а также отраслевой науки и проектных институтов. «То есть, приватизация обернулась экономической катастрофой» [6].

Неудачными считает реформы 90-х гг. и Я. М. Миркин, отмечающий разрушение российской экономики, в результате чего по объему промышленного производства за 2016 г. страна даже не достигла показателей 1990-1991 гг. «...идеология рыночного фундаментализма оказалась сильнее практичности», отмечает экономист [7].

Однако процесс приватизации продолжается, но уже через конкурсную продажу акций предприятий, находящихся под государственным контролем: предприятий, принадлежащих государству, или предприятий с государственным участием. В настоящее время в стране 765 акционерных обществ (АО) со $100 \%$ участием государства; 93 АО с участием государства от 50 до $100 \%$; 172 АО с участием государства от 25 до $50 \%$ и $674 \mathrm{AO}$, в которых участие государства менее $25 \%$.

Различают «малую приватизацию», которая касается предприятий, не играющих существенной роли в экономике, и «большую приватизацию». Вторая имеет отношение к предприятиям, влияющим на развитие как отдельных отраслей, так и в целом отечественной экономики. Поэтому вопрос об их приватизации решается руководством страны в условиях непростых дискуссий и занимает определенное время. Целью современной приватизации провозглашается рост темпов экономического развития через формирование и развитие конкурентной среды. Непосредственным же результатом является пополнение доходной части государственного бюджета.

${ }^{1} \mathrm{O}$ внесении изменений в подраздел 3 раздела 1 части первой Гражданского кодекса Российской Федерации : федер. закон от 2 июля 2013 г. № 142-ФЗ // СПС «КонсультантПлюс».

\section{Baikal Research Journal}

электронный научный журнал Байкальского государственного университета 
Предприятия, готовящиеся к приватизации, включаются в Приватизационный план страны. План приватизации 2014-2016 гг. предполагал ежегодные поступления в бюджет в размере 3 млрд р. В план приватизации 2017-2019 гг., одобренный на заседании Правительства РФ 2 февраля 2017 г., заложены ежегодные поступления в бюджет в размере 5,6 млрд р. Уточняется, что приведенная сумма должна поступать от "малой приватизации», не учитывающей поступления от продажи крупнейших активов, которые будут реализовываться с учетом рыночной конъюнктуры. В частности, на 2017 г. планируется поступление от приватизации порядка 138 млрд р. Поскольку правительство с осторожностью подходит к разгосударствлению экономически значимых активов, нередка ситуация, когда приватизация того или иного предприятия переносится на более поздний срок. Так, из плана 2014-2016 гг. в план 2017-2019 гг. перенесена приватизация акционерного общества Совкомфлот, которая намечалась на март-апрель 2017 г. От сделки правительство планирует выручить около 30 млрд р., тогда как в 2015 г. от этой сделки планировалось выручить 24 млрд р.

Однако уже в марте 2017 г. появились сообщения о продлении подготовки Совкомфлота к приватизации. По поручению вице-премьера И. И. Шувалова Росимущество к 15 мая должно разработать алгоритм сделки по приватизации, в июне начнется премаркетинг Совкомфлота, затем road-show, графика которого пока нет. Следовательно, сроком приватизации Совкомфлота можно считать конец первого-начало второго полугодия 2017 г.

Приватизация Совкомфлота активно обсуждается представителями государства и экономического сообщества. Рассмотрим этот вопрос подробнее.

Совкомфлот сегодня - это крупнейшая российская судоходная компания со штаб-квартирой в Санкт-Петербурге, которая специализируется на перевозке углеводородов, обслуживании шельфовой разведки и добычи нефти и газа. Совкомфлот работает, в том числе в условиях Арктики, что обусловливает уникальность его деятельности.

Предприятие образовано решением Совета Министров СССР в 1973 г. В 1988 г. Совкомфлот получил уникальный для того времени статус акционерного коммерческого предприятия с правом работать на зарубежных рынках. Учредителями выступили министерство морского флота СССР и советские судоходные предприятия. После распада СССР Совкомфлот в 1993 г. был преобразован в акционерную компанию. Сегодня в активе компании 146 судов, в том числе танкеров, газовозов, ледоколов и пр. По объему танкерных перевозок Совкомфлот занимает пятое место в мире. Отрицательный денежный поток был у Совкомфлота только один раз - в 2015 г. (по данным Bloomberg за 7 лет).

Совкомфлот на $100 \%$ принадлежит государству в лице Росимущества. В 2017 г. пройдет первый этап приватизации, на котором инвесторам будет предложено $25 \%$ минус одна акция, то есть, государство не потеряет контроль над стратегическим активом ${ }^{2}$. Однако по итогам трехлетней приватизации доля государства в капитале Совкомфлота должна сократиться до 25 \% плюс 1 акция. Эти намерения зафиксированы в Плане приватизации.

Приватизация Совкомфлота пройдет на Московской бирже. Инвестконсультантами выступят ВТБ Капитал и Сбербанк СІВ. Предполагается, что сделка будет комбинированная: продажа госпакета плюс дополнительная эмиссия акций. Новые акции составят 12,5 \% увеличенного уставного капитала. Еще 12,5 \% продаст Росимущество. Полученные от приватизации средства будут распределены следующим образом: 75 \% - в пользу государства, $25 \%$ - в пользу компании.

\footnotetext{
2 «Совкомфлот» - приватизация или потихоньку распродаемся? [Электронный ресурс]. URL: http://ehorussia.com/new/node/13699.
}

\section{Baikal Research Journal}


Как сообщил министр экономического развития М. С. Орешкин, докапитализация компании позволит снизить ее долговую нагрузку и стоимость заимствований. Средства будут потрачены на покупку новых судов, построенных в РФ, что будет способствовать развитию отечественного судостроения [8]. Положительным результатом приватизации Совкомфлота М. С. Орешкин считает также рост качества корпоративного управления, в чем сомневаются некоторые аналитики. По их мнению, поскольку контрольный пакет акций в 2017 г. останется в руках государства, миноритарии не смогут значимо влиять не деятельность компании. Активизация возможна, если в качестве акционеров «придут нефтяники» ${ }^{3}$.

По мнению ряда экспертов, заинтересованность в покупке Совкомфлота могут проявить российские нефтяные компании, финансовые инвесторы, например, Российский фонд прямых инвестиций (РФПИ) и его партнеры из Китая и Ближнего Востока, а также иностранные инвесторы из отрасли, например, арабский оператор DP World. Tакже говорится о возможном участии в сделке итальянского банка Intesa Sanpaolo, который выступил инвестконсультантом и основным кредитором при приватизации 19,5 \% акций Роснефти - крупнейшей приватизационной сделки 2016 г. ${ }^{4}$

Председатель Совета директоров банка Intesa подтвердил его возможное участие в сделке по приватизации Совкомфлота, если последует приглашение от руководства судоходной компании.

В конце марта 2017 г. в Министерстве экономического развития РФ прошла встреча замминистра с крупнейшими участниками пенсионного рынка и управляющими компаниями, на которой обсуждалось участие пенсионных фондов в размещении акций Совкомфлота. Препятствием для участия негосударственных пенсионных фондов (НПФ) в приватизации являются законодательные требования - нахождение акций приватизируемых компаний в высшем котировальном списке биржи и в индексном списке Московской межбанковской валютной бирже (ММВБ). Для акций, не входящих в индексный список, установлен лимит в $10 \%$, который обычно выбран, а для акций из индексного списка - $40 \%$. По мнению экспертов, должны быть сделаны исключения: или Московской биржей для Совкомфлота для попадания в индексный список, или Банком России для НПФ по отмене лимита 10 \% в сделках по приватизации. Известно, что Минэкономразвития и Банк России по итогам рабочей встречи выработали позицию о достаточности 10 \% лимита для НПФ при приватизации Совкомфлота, учитывая значительный спрос со стороны других инвесторов [9].

Современную приватизацию госпредприятий активно поддерживает академик А. Г. Аганбегян, который считает пополнение дефицитного бюджета ее утилитарной задачей, тогда как главная задача - восстановление экономического роста через увеличение доли частного бизнеса в экономике как более эффективного. В настоящее время, по его расчетам, 65 \% валового продукта производится на предприятиях под контролем государства, что отвлекает государство от выполнения его основных функций - заниматься проблемами людей. Под видом государства работают обычные коммерческие организации, которые занимаются самообогащением и разоряют государство. По мнению А. Г. Аганбегяна доля госбюджета в ВВП должна сократиться до $30 \%$, а доля предприятий и организаций под государственным управлением должна снизиться с 65 до 45 \% . Долю частного сектора следует довести до 55 \% [10].

Вопрос о доле государства в экономике в сентябре 2016 г. поднял руководитель Федеральной антимонопольной службы (ФАС) И. Ю. Артемьев. По его информации в 2005 г. в государственном секторе экономики создавалось $35 \%$ ВВП, а в

${ }^{3}$ URL: http://ehorussia.com/new/node/13699.

${ }^{4}$ URL: https://lenta.ru/news/2017/01/19/sovkomflot_privatizatsia/.

\section{Baikal Research Journal}

электронный научный журнал Байкальского государственного университета 
2015 г. этот показатель вырос до 70 \%, из чего следует, что государство «душит» конкуренцию, подрывает основы рыночной экономики. Многие чиновники из финансово-экономического блока правительства оперировали этим же аргументом на последнем Гайдаровском форуме. Однако, ими озвучивались различные цифры доли государства в создании валового внутренннго продукта (ВВП) РФ: в 50, 60 и $70 \%$. Это показывает, что у каждого чиновника своя «личная» статистика.

Профессор В. Ю. Катасонов приводит интересный расчет. Он допускает, что участие государства в создании ВВП составляет $50 \%$. Это минимальная из прозвучавших на Гайдаровском форуме оценок, ее в частности приводил Минэкономразвития. Ее, замечает В. Ю. Катасонов, интересно сравнить с некоторыми другими показателями, которые можно найти на сайте Росстата. Например, оценить долю государственного сектора с помощью показателя «основные фонды». В начале 1990-х гг. (до приватизации) в государственном секторе, по данным Росстата, находилось около $90 \%$ основных фондов российской экономики. К 2000 г. (после приватизации 90-х гг.) этот показатель упал до $25 \%$. В 2010 г. он опустился до $19 \%$, а в настоящее время составляет всего $18 \%$. Следовательно, при доле государства в основных фондах, равной $18 \%$, оно создает $50 \%$ ВВП страны (а И. Ю. Артемьев, а также И. И. Шувалов настаивают на 70 \%). Отсюда, на частный сектор приходится более 80 \% основных фондов и всего 50 \% или даже $30 \%$ создаваемого ВВП. Напрашивается вывод: частный сектор не эффективен, а для экономического восстановления (или даже рывка) необходимо усиление позиций государства. Вывод В. Катасонова: нужна не приватизация, а национализация.

Всего в 2017-2019 гг. планируется приватизировать 477 АО, 298 федеральных государственных унитарных предприятий, доли РФ в десяти обществах с ограниченной ответственностью, а также 1041 объект имущества государственной казны. За три года приватизационная программа даст в бюджет без малого 17 млрд р. Значит, в расчете на один из 1826 объектов приватизации средняя выручка составит 9,2 млн р., что, как замечает В. Катасонов, соответствует стоимости скромной московской квартиры. Бюджет РФ на 2017 г. предполагает расходную часть в размере 16,2 трлн р. Доходы от приватизации, запланированные на этот год (5,8 млрд р.) составят лишь $0,04 \%$ по отношению к бюджетным расходам. Такой бюджетный эффект эквивалентен введению или повышению любого акциза (на водку, ювелирные изделия, иные предметы роскоши). Также это меньше, чем годовая прибыль многих компаний и организаций, включенных в программу приватизации (годовая прибыль Совкомфлота составляет 400 млн дол.).

Некоторые члены правительства достаточно трезво подходят к оценке принятой программы приватизации. Так, министр экономического развития М. С. Орешкин в интервью газете Financial Times подчеркнул, что для оживления российской экономики необходима здоровая конкуренция, приватизация как таковая не поможет: «Если мы просто приватизируем крупные государственные компании, которые доминируют в определенных секторах, то конкурентная ситуация не улучшится, и не окажет серьезного влияния на общий рост» [11].

По мнению С. Ю. Глазьева, «приватизация должна планироваться исходя из общего плана управления государственным имущественным комплексом» и не должна привязываться к проблеме дефицитного бюджета, которая во всем мире решается через государственные заимствования [6].

Президент Союза предпринимателей и арендаторов России А. П. Бунич, говоря о нынешней приватизации, заявляет, что «Путь, который избрал экономический блок правительства, - тупиковый, а упорство, с которым правительство действует, вызывает недоумение». Его поддерживает экономист, бывший зампред Счетной палаты Ю. Ю. Болдырев, считающий современную приватизацию «на-

\section{Baikal Research Journal}


много более вредной, нежели приватизация Чубайса. ... это диверсия против народа и государства. Распродавать стратегические активы, такие как «Совкомфлот», да еще на пике низких цен, - преступление» ${ }^{5}$.

Мнений, подобных приведенным выше, очень много. Отрицательное отношение к современной приватизации крупных прибыльных государственных активов высказывают известные экономисты и профессиональные аналитики. Примечательно, что их доводы не являются «голым» теоретизированием, а опираются на статистические данные и расчеты, а также на здравый смысл.

Суммируя вышеприведенные мнения как сторонников, так и противников нынешней приватизации, можно сделать следующие выводы:

1. У правительства отсутствует стратегический план оптимизации управления государственной собственностью, который может включать в себя:

- приватизацию активов, принадлежащих государству;

- повышение качества управления госактивами без передачи их частному капиталу;

- национализацию экономически значимых активов при неэффективности их использования негосударственными собственниками.

2. Отсутствуют четко сформулированные цель и задачи приватизации. Каждый автор-сторонник приватизации по-своему формулирует положительные результаты, к которым она приведет. Высказывания членов правительства, судя по отзывам в прессе, не обоснованы, поэтому звучат неубедительно.

3. Не продуман детально механизм приватизации, все делается «на ходу». В частности, непрозрачен состав участников сделок, что вызывает сомнения в их чистоте. При этом факт допуска к покупке прибыльной государственной недвижимости избранных российских и иностранных инвесторов является очевидным.

4. Вызывает сомнение эффективность использования средств, полученных государством от продажи своих активов. Общие заявления о пополнении государственного бюджета и расходовании средств на государственные нужды не убеждают в том, что привлеченные ресурсы не уйдут «в никуда». Наоборот, возникает уверенность в том, что новая приватизация не будет способствовать росту благосостояния населения.

\section{Список использованной литературы}

1. Самаруха В. И. Приватизация промышленных предприятий России : монография / В. И. Самаруха. - Иркутск : Вост.-Сиб. кн. изд-во, 1998. - 127 с.

2. Приватизация по-российски / М. Бойко [и др.] ; под ред. А. Б. Чубайса. - М. : Вагриус, $1999 .-366 \mathrm{c}$.

3. Перевалов Ю. В. Анализ влияния приватизации на деятельность промышленных предприятий / Ю. В. Перевалов, И. Э. Гимади, В. В. Добродей. - М. : Рос. программа экон. исслед., 2000. -96 с.

4. Пивоваров С. Е. Постприватизационное развитие предприятий, комплексов, отраслей / С. Е. Пивоваров. - СПб. : Питер, 2004. - 382 с.

5. Кара-Мурза С. О приватизации и национализации [Электронный ресурс] / С. Кара-Мурза. - Режим доступа: http://mnenie.me/kara-murza-o-privatizacii-i-nacionalizacii.html.

6. Глазьев С. Бенефициарами этой приватизации могут стать спекулянты [Электронный ресурс] : [интервью советника президента] / записал Р. Фаляхов. - Режим доступа: https://www.gazeta.ru/business/2016/02/08/8062997.shtml.

7. Миркин Я. Почему экономика не растет? / Я. Миркин // Аргументы и факты. 2017. - 19 aпр. (№ 16). - С. 6.

8. Зиброва А. Приватизация «Совкомфлота» поддержит судостроителей [Электронный peсурс] / А. Зиброва, М. Папченкова. - Режим доступа: http://www.vedomosti.ru/ business/articles/2017/03/15/681164-privatizatsiya-sovkomflota.

${ }^{5}$ Страна за копейку. URL: https://versia.ru/rossiyu-zhdyot-novaya-privatizaciya-bessmyslennayai-besposhhadnaya.

\section{Baikal Research Journal}


9. Вержбицкий А. Фрахт пенсионеров: правительство хочет привлечь средства НПФ для приватизации «Совкомфлота» [Электронный ресурс] / А. Вержбицкий. - Режим доступа: http://www.forbes.ru/kompanii/341361.

10. Аганбегян А. Г. Задача - восстановить рост [Электронный ресурс] / А. Г. Аганбегян. Режим доступа: http://www.sib-science.info/ru/news/akademik-abel-aganbegyan-o-23052016.

11. Катасонов В. Россию распродадут за бесценок [Электронный ресурс] / В. Катасонов. - Режим доступа: http://svpressa.ru/economy/article/166636/.

\section{References}

1. Samarukha V. I. Privatizatsiya promyshlennykh predpriyatii Rossii [Privatization of Russia's industrial companies]. Irkutsk, Vostochno-Sibirskoe knizhnoe izdatel'stvo Publ., 1998. $127 \mathrm{p}$.

2. Boyko M. et al.; Chubais A. B. (ed.). Privatizatsiya po-rossiiski [Privatization in the Russian way]. Moscow, Vagrius Publ., 1999. 366 p.

3. Perevalov Yu. V., Gimadi I. E., Goodday V. V. Analiz vliyaniya priva-tizatsii na deyatel'nost' promyshlennykh predpriyatii [Analysis of privatization impact on performance of industrial companies]. Moscow, Russian Program of Economic Research Publ., 2000. 96 p.

4. Pivovarov S. E. Postprivatizatsionnoe razvitie predpriyatii, kompleksov, otraslei [Post-privatizational development of enterprises, complexes, branches]. Saint Petersburg, Piter Publ., 2004. 382 p.

5. Kara-Murza S. O privatizatsii $i$ natsionalizatsii [On privatization and nationalization]. Available at: http://mnenie.me/kara-murza-o-privatizacii-i-nacionalizacii.html. (In Russian).

6. Glazyev S.; Falyakhov R. (ed.). Benefitsiarami etoi privatizatsii mogut stat' spekulyanty [Profiteers can become the beneficiaries of this privatization]. Available at: https://www.gazeta.ru/business/2016/02/08/8062997.shtml. (In Russian).

7. Mirkin Ya. Why is economy not growing? Argumenty $i$ fakty $=$ Arguments and Facts, 2017, April 19 (no. 16), p. 6. (In Russian).

8. Zibrova A., Papchenkova M. Privatizatsiya «Sovkomflota» podderzhit sudostroitelei [Privatization of «Sovkomflot» Company will support shipbuilders]. Available at: http://www. vedomosti.ru/business/articles/2017/03/15/681164-privatizatsiya-sovkomflota. (In Russian).

9. Verzhbitsky A. Frakht pensionerov: pravitel'stvo khochet pri-vlech' sredstva NPF dlya privatizatsii «Sovkomflota» [Freight of pensioners: the government wants to attract the resources of National Pension Fund for privatization of «Sovkomflot» Company]. Available at: http://www.forbes.ru/kompanii/341361. (In Russian).

10. Aganbegyan A. G. Zadacha - vosstanovit' rost [The task is to restore the growth]. Available at: http://www.sib-science.info/ru/news/akademik-abel-aganbegyan-o-23052016. (In Russian).

11. Katasonov V. Rossiyu rasprodadut za bestsenok [Russia is going to be sold for a song]. Available at: http://svpressa.ru/economy/article/166636/. (In Russian).

\section{Информация об авторе}

Дубовик Ирина Владилировна - кандидат экономических наук, доцент, кафедра банковского дела и ценных бумаг, Байкальский государственный университет, 664003, г. Иркутск, ул. Ленина, 11, e-mail: ivd@bk.ru.

\section{Author}

Irina V. Dubovik - PhD in Economics, Associate Professor, Chair of Banking and Securities, Baikal State University, 11 Lenin St., 664003, Irkutsk, Russian Federation; e-mail: ivd@bk.ru.

\section{Библиографическое описание статьи}

Дубовик И. В. Современная приватизация: за и против / И. В. Дубовик // Baikal Research Journal. - 2017. - T. 8, № 2. - DOI: 10.17150/2411-6262.2017.8(2).13.

Reference to article

Dubovik I. V. Modern privatization: pro et contra. Baikal Research Journal, 2017, vol. 8, no. 2. DOI: 10.17150/2411-6262.2017.8(2).13. (In Russian).

\section{Baikal Research Journal}

